
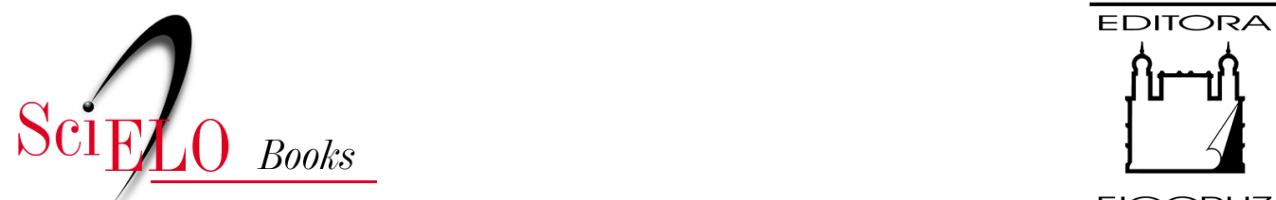

FIOCRUZ

\title{
$\underline{\text { O cuidado com a morte na contemporaneidade }}$
}

Rachel Aisengart Menezes

\section{SciELO Books / SciELO Livros / SciELO Libros}

MENEZES, R. A. O cuidado com a morte na contemporaneidade. In.: Em busca da boa morte: antropologia dos cuidados paliativos [online]. Rio de Janeiro: Garamond; Editora FIOCRUZ, 2004, pp. 15-23. ISBN: 978-655708-112-9. https://doi.org/10.7476/9786557081129.0002.

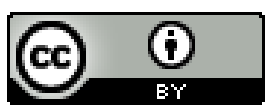

All the contents of this work, except where otherwise noted, is licensed under a Creative Commons Attribution 4.0 International license.

Todo o conteúdo deste trabalho, exceto quando houver ressalva, é publicado sob a licença Creative Commons Atribição 4.0.

Todo el contenido de esta obra, excepto donde se indique lo contrario, está bajo licencia de la licencia Creative Commons Reconocimento 4.0. 


\section{O CUIDADO COM A MORTE NA CONTEMPORANEIDADE}

Em 1999, ao pesquisar em um Centro de Tratamento Intensivo de um hospital público universitário, presenciei a morte solitária de um senhor de oitenta anos, esquizofrênico crônico, cardíaco, com câncer e múltiplas metástases, conectado a aparelhos e amarrado às grades do leito. Acompanhei diversas situações semelhantes, nas quais pacientes diagnosticados como "fora de possibilidades terapêuticas" (FPT), com prognóstico de morte próxima, faleceram com seus corpos invadidos por tubos, sem a presença de familiares. O doente FPT é aquele para o qual a medicina não possui mais recursos para deter o avanço fatal da doença, trazendo interrogações para equipes de saúde, familiares e para o próprio indivíduo.

O que fazer com este paciente? Como administrar seu final de vida? Justifica-se a manutenção do aparato tecnológico quando não há mais esperança de cura? Quando interromper o tratamento curativo? Que vida é possível para este doente, a partir de sua categorização como FPT?

Estas - e outras - indagações então surgiram, configurando a temática sobre a qual me debrucei, até me ver imersa na causa da "boa morte". O contato ocasional com um livro' francês, que suscitou amplos debates naquele país, me informou sobre uma nova proposta de assistência aos doentes terminais ou FPT, denominada Projeto Hospice ${ }^{2}$ ou Cuidados

\footnotetext{
'La mort intime. Ceux qui vont mourir nous apprennent à vivre, de autoria da psicanalista Marie de Hennezel (1995). O livro é prefaciado por François Mitterrand, ex-presidente francês que, por sofrer de um câncer generalizado, ao final de sua vida decidiu ser cuidado pela equipe de Hennezel. Em 1996 morreu em sua residência, conforme seu desejo.

${ }^{2}$ Utilizo o termo hospice no original, em inglês, uma vez que não há equivalente em português.
} 
Paliativos, cujo principal objetivo é a "humanização" do morrer. Era uma nova modalidade de gestão do período final de vida. Quando busquei mais informações sobre o tema na literatura, soube do aparecimento no Brasil de unidades hospitalares regidas por esse novo modelo.

O processo vivido pelos pacientes que já vislumbram o final da vida - situados em um lugar-tempo especial e aguardando a chegada de sua morte anunciada - e os cuidados a eles ministrados por uma equipe de saúde voltada para minorar seu sofrimento e conduzi-los à "boa morte" me envolveram a tal ponto que decidi empreender uma pesquisa. A investigação sobre os Cuidados Paliativos se ampliou, transformando-se em tese de doutoramento. ${ }^{3}$

Para investigar os Cuidados Paliativos, iniciei um percurso: busquei suas origens, as transformações históricas e sociais das atitudes face à morte e ao morrer, chegando a uma literatura analítica sobre o tema. Voltei-me para os ideólogos da causa da boa morte, encontrando uma extensa produção inglesa e norte-americana e fui informada da criação de uma nova especialidade médica, a Medicina Paliativa - já reconhecida em vários países, como Canadá, Estados Unidos, Inglaterra, entre outros. Buscando conhecer de mais perto este campo profissional, pesquisei na Internet e achei associações, profissionais e leigas, dedicadas ao ensino, pesquisa e divulgação do novo modelo do morrer. Quando tomei conhecimento de uma lista de discussão internacional, com base na Inglaterra, exclusivamente dedicada aos Cuidados Paliativos, me inscrevi como participante. Passei a receber mensagens de médicos, enfermeiros, farmacêuticos e psicólogos discutindo seu exercício prático, suas dúvidas e dilemas cotidianos nos cuidados aos doentes FPT e a seus familiares.

Em pouco tempo, tive acesso a uma extensa bibliografia estrangeira sobre os Cuidados Paliativos. Contudo, as informações sobre o assunto em nosso país são difíceis e escassas: dirigi-me à primeira unidade pública paliativa no país - o Hospital do Câncer IV do Instituto Nacional do Câncer, no Rio de Janeiro, solicitando conhecer a instituição e coletar dados sobre a implementação prática deste modelo de assistência. Iniciei então

\footnotetext{
${ }^{3}$ Doutorado em Saúde Coletiva, área de Ciências Humanas e Saúde, no Instituto de Medicina Social da Universidade do Estado do Rio de Janeiro.
} 
uma longa trajetória, com idas e vindas, percalços e dificuldades - indicativos das representações correntes no Brasil sobre o processo de morte.

Tomei conhecimento de eventos profissionais sobre os Cuidados Paliativos. Decidi observá-los. Na II Jornada Nacional de Cuidados Paliativos e da Dor ("Corpo, mente e alma em foco"), no Rio de Janeiro, constatei a construção de uma identidade comum aos profissionais de Cuidados Paliativos: a de militante da causa da humanização do morrer. Um segundo evento, o Simpósio Nacional de Cuidados Paliativos (São Paulo), organizado em 2003 pela Sociedade Brasileira de Clínica Médica, confirmou a existência de uma militância ativa, em nosso país, de profissionais de saúde ligados à causa da boa morte.

Estes passos confirmavam minha escolha. Queria dedicar-me ao tema dos cuidados contemporâneos aos que vivenciam o processo lento do morrer em consequiência de doença crônica degenerativa como, por exemplo, o câncer. Para saber como a proposta é implementada na prática cotidiana de um hospital público, visitei o Hospital do Câncer IV em 2001. Ciceroneada por uma psicóloga do serviço, fui apresentada à instituição, conheci sua estrutura física, sua equipe e clientela. Esta visita me provocou um impacto positivo, pela receptividade dos profissionais e pelas instalações modernas, limpas e organizadas. O contato com os doentes ali atendidos foi um segundo impacto, contrastante com o primeiro: são todos pessoas visivelmente doentes, magras, enfraquecidas, com sofrimento e dor aparentes, algumas com deformidades em decorrência de tumores e/ou cirurgias. Parte dos pacientes internados estava acompanhada de familiares, que aparentavam cansaço, ansiedade e preocupação, enquanto outros pacientes pareciam contar apenas com a equipe institucional.

A imersão havia começado. A observação da Jornada e a visita ao Hospital do Câncer IV reafirmaram minha escolha de investigar o funcionamento, na prática, da assistência paliativa neste hospital. Para isso, era preciso autorização do Comitê de Ética do Instituto Nacional do Câncer. Ainda em 2001, apresentei os documentos necessários à abertura de processo de solicitação de "visita de observação", concedido apenas a profissionais de saúde. A resposta foi positiva: poderia freqüentar o hospital durante dois meses. A permissão se restringia à observação das 
atividades da equipe, não incluindo a realização de entrevistas gravadas. Eu deveria me apresentar na data marcada, de jaleco branco, pois "assim pacientes e familiares poderão saber que trata-se de uma médica e não uma acompanhante", segundo uma profissional do Instituto Nacional do Câncer.

Iniciei o período de observação, durante o qual assisti aos cursos para estagiários e participei de reuniões formais e informais. Busquei conhecer a maior parte dos setores e das formas de assistência do hospital pioneiro em Cuidados Paliativos no Brasil. Acompanhei profissionais em visitas domiciliares, assisti a atendimentos ambulatoriais e nas enfermarias. Ao perceber aceitação maior da minha presença por parte de determinados profissionais ou ém certas reuniões, privilegiei estes espaços. Tive contato com a complexidade e delicadeza da tarefa da equipe em várias situações. Por exemplo, quando havia piora da condição de um paciente e o médico informava a iminência da morte a seu acompanhante eu ficava por perto do profissional e, caso surgisse demanda de escuta, demonstrava minha disponibilidade ao familiar.

A necessidade de permanecer um período maior no hospital ficou evidente. Solicitei nova autorização, incluindo a possibilidade de gravar entrevistas com profissionais, com consentimento informado. Iniciou-se um extenso período em busca da aprovação, que teve diversos entraves burocráticos: documentos perdidos e mais adiante encontrados; o próprio processo desapareceu, sendo reencontrado e reencaminhado; novas exigências e assinaturas. Transcorridos seis meses, eu ainda não havia recebido a resposta: parecia que minha pesquisa tinha sido classificada da mesma forma que os doentes assistidos pelos Cuidados Paliativos - "fora de possibilidades".

Finalmente, após a entrega de toda a documentação exigida, do preenchimento de formulários, além da reiteração de que se tratava de pesquisa qualitativa - o que certamente causou estranheza aos leitores do projeto -, fui aprovada. Iniciei um segundo período de observação, do final de 2002 até junho de 2003, quando entrevistei 21 profissionais do hospital.

A decisão de tomar os Cuidados Paliativos como tema de pesquisa causou basicamente dois tipos de reação em meu círculo social: um, 
positivo, valorizando a temática por sua atualidade; e outro, negativo, derivado do contato com o sofrimento. O comentário de alguns antropólogos, no que se refere ao sofrimento, foi de que se trata de "um assunto tão pesado e doloroso". Face à escolha, um deles perguntou-me porque não optei por um campo de observação "mais ameno, em contato com a natureza", o que foi reiterado por outra antropóloga, que disse preferir a pesquisa na "selva, do que ficar confinada em hospital". Outros expressaram suas observações sobre o objeto desta pesquisa empregando um referencial psicopatológico, como a sugestão que me fizeram de que retornasse a um tratamento psicanalítico, ou a interpretação de que a escolha seria "masoquista". Uma amiga advertiu-me sobre os riscos de depressão ao trabalhar "tanto com a morte". Outra disse que minha opção era "meio mórbida". Estas opiniões reafirmam a associação da morte com as idéias de depressão, pesar, sofrimento, perversão, e sugerem que esta temática deve ser mantida à distância da vida saudável. Em última instância, a escolha de investigar as práticas profissionais em torno da morte e do morrer seria, para muitos, indício de afastamento da normalidade psicológica. ${ }^{4}$ David Sudnow, ${ }^{5}$ entre outros autores, refere-se ao estigma que recai sobre os indivíduos que se relacionam profissionalmente com cadáveres e sobre os que investigam a temática da morte. Mas as reações não foram apenas negativas: muitos amigos consideraram a opção de pesquisa corajosa. Coragem foi o termo utilizado, aludindo a uma característica pessoal de resistência necessária ao desenvolvimento da investigação.

Qualquer imersão em um campo de pesquisa desperta sentimentos e emoções: o contato com a doença, o sofrimento e a morte causou-me grande angústia. É imprescindível refletir sobre os sentimentos que emergiram no exercício cotidiano junto aos profissionais de saúde e suas representações. A proposta de assistência paliativa ainda é praticamente desconhecida no meio médico e na sociedade brasileira em geral. Ao longo da observação, fui introduzida em um novo universo de saberes e práticas. A

\footnotetext{
${ }^{4} \mathrm{O}$ modelo de normalidade contemporâneo é passível de discussão, mas sabe-se que são valores preeminentes em nossa sociedade a busca de prazer, da beleza e da manutenção da juventude.

${ }^{5}$ Sudnow, 1967.
} 
obrigatoriedade de usar jaleco, com crachá de identificação como médica visitante, envolveu-me em situações complexas e delicadas na relação com os observados. Minha dupla identidade - de médica e de pesquisadora conduziu-me à reflexão ética sobre meu posicionamento no campo.

Em minha observação, apreendi as práticas e a lógica de um grupo profissional. A partir da visão e da escuta dos atores observados, o pesquisador constrói a sua versão: uma entre outras possíveis.

De acordo com os divulgadores dos Cuidados Paliativos, a proposta de oferecer uma assistência não mais curativa, e sim voltada a cuidar e aplacar o sofrimento, surǵiu em contraposição à prática médica eminentemente tecnológica e institucionalizada, na qual o doente é excluído do processo de tomada de decisões relativas à sua vida e à própria morte. Com o advento e a implementação prática desta nova abordagem, o processo do morrer passou a ser debatido entre todos os envolvidos profissionais, doentes e seus familiares -, gerando assim uma forma diferente de administração do período final da vida do enfermo. Surgem novos profissionais e uma especialidade orientada para o último período da vida do doente. Os Cuidados Paliativos, seus ideólogos e instituições buscam criar uma nova representação social do morrer, viabilizada pela construção de modalidades inovadoras de relação entre profissionais de saúde e doentes/familiares, inseridas em novas práticas institucionais. $\mathrm{O}$ funcionamento destas unidades hospitalares de Cuidados Paliativos é regido por uma extensa produção discursiva acerca do processo de tomada de decisões relativas à doença, ao sofrimento e à morte.

Poucas décadas passaram-se desde o início da implementação prática desta proposta, no entanto, foram suficientes para promover diversas transformações sociais relativas à morte. Neste período, as representações coletivas da morte e do final da vida sofreram diversas mudanças, traduzindo o surgimento de preocupações suscitadas pela gestão do morrer. A morte adquiriu outros significados, atribuídos pelos defensores dessa organização social para o morrer. O doente FPT passou a ser objeto de estudos e de pesquisas, propiciando a criação de uma discipli- 
na científica, voltada para a etapa final da vida e uma fase específica da doença. Este doente, antes ignorado e abandonado pelo saber médico e suas instituições, é investido de um valor positivo pelos ideólogos e profissionais da causa da "boa morte". A produção e difusão de discursos, conjugadas à criação de um novo espaço social, indicam uma mudança no sistema de valores, nas representações e nas sensibilidades contemporâneas relativas à morte e ao morrer. Pesquisadores de diversas áreas - Ciências Sociais, Psicologia, Direito, Medicina, Filosofia, História, Ética e Bioética - debruçam-se sobre esta construção, a ponto de postularem um "renascimento da morte" transformações sociais ocorridas.

Constato o surgimento do novo modelo de morte, nomeado por diversos autores como morte "pós-moderna", "neo-moderna" ou "contemporânea". A idéia da existência de diferentes modelos de morte remete-se às formulações do historiador Philippe Ariès ${ }^{7}$ que, em suas pesquisas sobre as atitudes sociais face a este evento, identificou duas configurações sociais e simbólicas diferentes, associadas a momentos históricos distintos: morte "tradicional" e morte "moderna". A oposição tradicional/moderno é tomada aqui neste livro como instrumento preliminar de análise e não deve ser reificada. São noções simplificadas sobre a vida social, de modo que dificilmente podem ser encontrados em sua forma pura. Os aspectos diferenciais de cada modelo referem-se ao contexto social, ao sistema de autoridade regente, às concepções de corpo, morte e luto, e aos valores prevalecentes e crenças associadas à morte em cada conjuntura. Minha escolha por trabalhar com esta modelização deve-se ao seu valor heurístico, uma vez que sua utilização conduz a hipóteses, indagações e descobertas. Cada um dos modelos tende a suceder o prévio, em seqüência temporal e histórica. Apesar de estarem associados a períodos históricos distintos, podem coexistir em uma mesma sociedade, em um mesmo momento histórico.

Para investigar o modelo recente de morte - o "contemporâneo" - foi necessário analisar o contexto histórico e cultural que gerou este cons-

\footnotetext{
${ }^{6}$ Tony Walter, 1997.

${ }^{7}$ Ariès, 1981a; 2003.
} 
tructo. Ao longo do século XX, as condições da morte foram profundamente transformadas. O hospital, seus saberes e profissionais passaram a ocupar, na sociedade ocidental, um lugar central e quase naturalizado no que concerne à prestação de serviços direcionados à saúde, à doença e à morte. A partir da Primeira Grande Guerra, e mais aceleradamente após a Segunda Guerra, foram desenvolvidas diversas tecnologias que acarretaram uma racionalização do morticínio em massa e o desenvolvimento de uma prática médica padronizada e tecnologizada. Com a evolução de técnicas e tecnologias médicas, tornou-se possível um certo prolongamento do tempo de vida, o que viabilizou idéias concebidas originalmente pela ficção científica, como a criogenia.

As possibilidades de reanimação, alimentação e respiração artificiais contribuem para a expansão das fronteiras da vida. A oferta do aumento do tempo de vida leva à possibilidades de resoluções diversas, provocando uma discussão ética relativa ao período que precede a morte e à sua própria determinação temporal. São construídos o conceito e o diagnóstico de morte cerebral, em função do transplante de órgãos. A morte de distintas partes do corpo tornou-se as mortes sucessivas do mesmo indivíduo mediante a tecnologia médica. ${ }^{8}$ A medicina revela sua incapacidade de administrar os casos limites, engendrados por seus saberes e técnicas.

A proposta dos Cuidados Paliativos insere-se, portanto, na discussão ética relativa à administração do período final de vida do doente pela medicina, seus saberes, seus profissionais e suas instituições. Ao pesquisar esta nova proposta, procurei apreender o objeto pesquisado sob múltiplas leituras. Do ponto de vista sócio-histórico, busco compreender o surgimento de uma nova forma de relação profissional e social com o processo do morrer. Sob a ótica da antropologia, alcançar as práticas profissionais e os discursos produzidos sobre as mesmas.

Tomar como objeto de investigação o sofrimento e a perda conduz intrinsecamente a emoções e sentimentos. O processo de adaptação do pesquisador a um ambiente marcado pela onipresença da morte é, sem dúvida, um desafio doloroso. Apesar do contato concreto com a dor e

\footnotetext{
${ }^{8}$ David Le Breton, 1995:62.
} 
com os efeitos devastadores da doença constituírem uma carga emocional real, não desisti de meu estudo. Ao contrário, a relação com os profissionais, com os doentes FPT e seus familiares incentivaram-se a aprofundar minha imersão no hospital de Cuidados Paliativos. Assim, considerei meus sentimentos e as reflexões sobre os mesmos como dados importantes da observação etnográfica. A dificuldade de trabalhar no limiar da morte - seja para os profissionais de saúde e familiares dos pacientes, seja para pesquisadores - se revelou extremamente produtiva para a análise e compreensão dos problemas enfrentados no dia-a-dia deste hospital. Em suma, ao desenvolver esta pesquisa, me angustiei e sofri - mas hoje tenho a certeza de que, sem estas vivências, não teria conseguido escrever este livro. 